\title{
A Preliminary Study On Countermeasures For Optimizing the Ecological Environment of Language
}

\author{
Zhao Lin \\ Liaoning Economic Vocational \& Technical College, Shenyang, Liaoning Province, China
}

\begin{abstract}
Keywords: Countermeasures; CIIS; Optimizing the Ecological Environment of Language
\end{abstract}
\begin{abstract}
With the internationalization has been sweeping the world, Shenyang will be transformed into an international city through improving city internationalization level. The study will attempt to propose some countermeasures, such as, conducting the research on international language environment vs. economic development with (CIIS), making the exploration on international language environment, learning from the experience from international metropolises to optimize international language environment to achieve promoting Shenyang's international quality.
\end{abstract}

\section{Introduction}

Internationalization has swept the world. For the process of internationalization originates from the expansion of regional economy, the internationalization phenomenon is the most obvious in the regional economy. City internationalization refers to a city takes an active part in international divisions and collaboration, to the process and the degree of city life increasingly enters international economic and political life, to the important ways of promoting city management level and city comprehensive competitiveness internationally. United Nations put forward City Internationalization Index System in Istanbul Convention (table 1), in which there are five characteristics with 17 indicators reflecting international degrees in economic strength, infrastructure, human environment, quality of life, and is divided into primary, intermediate and advanced stages. Beijing has clearly planned to become a world city with Chinese characteristics in the 21 st century, Shanghai will become the international economic, financial, trade and shipping center, and" Guangzhou City Whole Plan (2010-2020)" is for Guangzhou becoming an international city .

Shenyang will become the center of the northeast Asia and an important international city through applying a series of international strategies put forward in the Revitalization of Development Goals (II) of 2030: to build Shenyang into a hub of international channel with the strategy of "One Belt, One Road"; Adhere to the policy of "Import \& Output" and form an international industrial configuration; Promoting the construction of free trade zones and adopting the policy of opening up to the outside world; Strengthen the city multi-cultural construction for displaying the functions of the international soft environment. More specifically emphasized that to build the international friendly environment for business, the platform of international elements gathering, making international brands, to realize the internationalization of regional industry, and to strengthen the international communication and cooperation on culture, sports, education, science and technology. Shenyang has a natural geographical position in inland. Comparing with the developed coastal areas, the opening-up of Shenyang is later and opening-up degree is not high, In this context, to promote city internationalization level is required to making a full comparison, looking for their own gap, and exploring an internationalization road with local characteristics.

\section{Literature review}

As early as 1959 , two scholars, Vinay \& Darbelne, began to study public signs. Vinay and Darbelne believe that, in order to achieve functional equivalence, it is often necessary to use compilation in order to achieve functional equivalence in the context of language culture. Connor believes that 
public signs are the focus of a particular group of people with achieving a specific purpose of communication (Connor,2001). In the early 1980 s, Canale\&Swain (1980) put forward relating to grammar ability, social ability of language skills, strategies, communication skills, which contains social language pragmatic competence, refers to the accuracy of language form and the meaning expressed by the appropriateness (RanYongPing 2006-48).

In China, Luo xuanmin,put forward that the translation of public signs was a serious problem in 2006. "Because of its particularity, diversity and complexity, tourism translation is still not well known and grasped by our translators" (huang youyi,2007:187). He Ziran proposes attention to the translation of public signs (Pi Demin,2010: 131-134). In 1998, he edited the paper " Construction of social Pragmatics", and discussed the translation of public signs and the common pragmatic mistakes from the perspective of pragmatics. Since then, more and more scholars have begun to participate in the research of this field.

\section{Research and Discussions}

\subsection{Purpose of the study}

To optimize the environment of Shenyang's international language, for Shenyang international strategy general objective, namely, become the center of northeast Asia important international in Shenyang city, construction into international hub, to strengthen the construction of city cultural diversity, the internationalization of soft environment function etc. this study is related to the results of linguistics and translation practice and has a positive impact to effectively promote the linguistic subject construction. The study attempts to apply linguistic theories to explore the city international language environment, looking forward to project achievements to realize Shenyang city's economic development, the implementation of the strategy of internationalization city has practical value. The analysis and comparison of the international language environment in Shenyang city under the city internationalization index system is of practical significance for optimizing the international language environment.

\subsection{Potential questions to be answered}

The study will address the following questions:

a. What are the countermeasures for optimizing city international language environment?

b. What are the existing problems, gaps and shortcomings of the situations of Shenyang's international language environment by comparing with the CIIS?

c. How to learn from the experience from internationalization of the world's international metropolis, and seek the advice for revitalizing development and internationalization of Shenyang under the new situation.

\subsection{Research methods}

The proposed study plans to be conducted with literature review, comparing test and survey approaches. In-depth interviews and journal writing will be used in the study as well.

\subsection{Results and Discussions:}

\subsubsection{The international language environment Promotes Economic development}

The language environment is an indirect investment environment, because the investment environment itself is a system and is a composite whole. The function of the system is composed of the functions of various elements. Only the functions of each element are fully realized, and the function of the system can reach its maximum. Language environment refers to the situation of language life of a region or a community, which is the basic appearance of the social use of language. In this paper, the "language environment" is the linguistic state of people in a certain time and space, which is a public language life and belongs to the category of sociolinguistics. Such as the 
compatibility of language attitudes, for foreign language, the language standardization degree, language civilization level, and so on all constitute a community or a basic aspect. The international metropolis must be the outlook of a multi-lingual city, and the attitude of the people towards foreign languages reflects the tolerance of a city to foreign culture and civilization. To a considerable extent, smooth economic activities depend on the language communications economic integration and that becomes more and more prominent today. Therefore, the potential market value of the international language environment is being favored by national governments, international investment communities and linguists.

\subsubsection{City internationalization index system}

UN Istanbul city annual conference released the Index System of city Internationalization (table 1) we found the "the percentage of foreign population, the number of inbound tourists, the population of people using English for exchange and the exchange rate of international major currencies, and these constitute of the essential factors of a city's opening, in which it is not hard to see international language environment as an important indicator of evaluation of city internationalization.

To survey the current situation of Shenyang's international language environment, and make the literature search, to compare and reference the City Internationalization Index System(CIIS), to analyze the cause and find out the gap and the insufficiency to propose the solutions in the paper or advice.

\subsubsection{Research on international language environment of Shenyang under City Internationalization} Index System (CIIS).

United Nations put forward Index system of City Internationalization Index System(CIIS) (table 1), in which there are five characteristics with 17 indicators reflecting international degrees in economic strength, infrastructure, human environment, quality of life, and is divided into primary, intermediate and advanced stages. Beijing has clearly planned to become a world city with Chinese characteristics in the 21st century, Shanghai will become the international economic, financial, trade and shipping center and "Guangzhou City Whole Plan (2010-2020) is for Guangzhou becoming an international city. Find out the gap and insufficiency in the environment of international language of Shenyang, to offer the basis and reference of making some countermeasures for optimizing the environment of international language.

\subsubsection{Research on how the international language environment affects the internationalization of Shenyang.}

The modernization level of the city is often closely related to the degree of language diversification, but an international metropolis must be a city with diverse languages. To a considerable extent, economic activities going smoothly depends on the language communications economic integration becomes more and more prominent today. Therefore, it is very important to study the relationship between soft environment of international language and city internationalization.

\subsubsection{Research on the experience from international metropolises.}

The program focuses on analyzing international trade, international migration, international migration, financial internationalization of several international metropolises, especially in the aspect of the degree of international language environment construction, to provide some suggestions and reference to enhance the level of internationalization development of Shenyang.
3.4.6 Research on optimizing the soft environment of international language and improve international quality countermeasures of Shenyang.
Under the background of Shenyang Internationalization Strategy, this study will try to raise the countermeasures to optimize the international language environment strategy and enhance Shenyang international quality and image. 


\section{Conclusion of the study}

It fits with the internationalization strategy that Shenyang just started, and it has the time. International: adopt the international research measures, based on the United Nations city international standard index system in Istanbul as the standard provide a rich and reliable basis and reference for the research by referring to the experience and practices of the cities with the highest internationalization level at home and abroad. From cultural soft power and linguistics as a research field, which is the perspective of optimizing city international language environment, the study is to propose some countermeasures to improve the quality of city internationalization for constructing the city, to perfect and expand the dimensions of this field of research.

\section{References}

[1] Wang Yanking, Countermeasures and Suggestions on the construction of language environment in the process of urban internationalization. Chinese journal, vol. 8, pp55-57, 2012.

[2] Lijun, Xudi, To optimize the city's theoretical research evaluation index and experience enlightenment,Municipal Administration and Technology,Vol4, pp31-33, 2017.

[3] Wang Faming, The construction of the comprehensive evaluation index system of the city's internationalization level,Decision Reference,22.008,2009.

[4] Dang lixin, Study on the relationship between the soft environment of foreign language culture and the image and economic development of Huaian,Culture Journal,Nov,vol. 11,pp84-88, 2017.

[5] Zeng Yiping, The language environment is also an investment environment, Journal of Jian University, Vol.20 No.1 pp109-116,1998

[6] Liuhongjuan, Heguoyong,On the Reference of London and New York and other internationalization Experience, Southern Review,vol.6,2015

[7] Songzehua,Accelerate the international language environment construction to help the city internationalization ,Huangzhou Daily, A14, 2014. 